\title{
La dictadura contra la Reforma Universitaria. Orientación de la política universitaria en la Universidad de Buenos Aires (1976-1983) ${ }^{1}$
}

\author{
The dictatorship against the University Reform. Orientation of the \\ university policy at the University of Buenos Aires (1976-1983)
}

\author{
A ditatura com a Reforma Universitária. Orientação da política \\ universitária na Universidade de Buenos Aires (1976-1983)
}

\author{
Guadalupe A. Seia ${ }^{2}$ \\ Universidad de Buenos Aires (Argentina)
}

Recepción: 20/05/2017
Evaluación: 08/01/2018
Aceptación: 05/01/2018
Artículo de investigación - Reflexión
DOI: https://doi.org/10.19053/01227238.8023

\section{RESUMEN}

En el presente artículo nos proponemos analizar la orientación de la política universitaria de la última dictadura en Argentina (1976-1983). Focalizamos sobre su posicionamiento respecto de la Reforma Universitaria de 1918 y su herencia, en tanto constituyó uno de los ejes principales de sus diagnósticos e intervención y es un aspecto que ha permanecido poco estudiado. Abordamos los discursos de las autoridades educativas a nivel nacional y los rectores interventores de la Universidad de Buenos Aires (UBA), principal casa de altos estudios del país. Asimismo, describimos la aplicación de la política universitaria dictatorial en dicha institución, dando cuenta de las transformaciones que buscaban imponerse. Por último, reconstruimos algunos de los conflictos y disputas que tuvieron lugar entre los actores universitarios de Buenos Aires sobre la política implementada.

Como conclusión, planteamos la orientación antireformista de la política universitaria dictatorial desarrollada en la UBA, fundamentalmente contra dos de sus pilares: el cogobierno y la autonomía universitaria. Sin embargo, sostenemos que a pesar de los objetivos propuestos por el régimen, el movimiento estudiantil

$1 \quad$ Este trabajo es fruto de Guadalupe Andrea Seia. "La Universidad de Buenos Aires (UBA) entre la "Misión Ivanissevich" y la última dictadura (1974-1983). Represión, "reordenamiento" y reconfiguraciones de la vida estudiantil" (Tesis de Maestría en Historia Contemporánea, Universidad Nacional de General Sarmiento, 2016). La misma fue desarrollada bajo la dirección del Dr. Pablo Buchbinder, en el marco de la Beca Interna Doctoral financiada por el Consejo Nacional de Investigaciones Científicas y Técnicas (CONICET).

2 Magíster en Historia Contemporánea (UNGS-Argentina). Becaria doctoral CONICET con lugar de trabajo en el Instituto de Historia Americana y Argentina "Dr. Emilio Ravignani”, Universidad de Buenos Aires (UBA), Consejo Nacional de Investigaciones Científicas y Técnicas. Investigadora Becaria en Proyecto UBACYT 200201301100187BA "Políticas públicas, universidad y movimiento estudiantil: 1969-1985”, Director Pablo Gabriel Buchbinder, Programación 2015-2017, Facultad de Ciencias Sociales, UBA. Auxiliar docente en la Carrera de Sociología de la Facultad de Ciencias Sociales, UBA. Correo electrónico: guadalupeseia@gmail.com 
recuperó dicha tradición hacia el final de la etapa dictatorial.

Para desarrollar este trabajo recurrimos a una estrategia metodológica de triangulación de fuentes primarias de diverso carácter (documentación ministerial, materiales de las Fuerzas Armadas, normativa universitaria, discursos de autoridades, notas periodísticas) y secundarias.

Palabras Clave: Revista Historia de la Educación Latinoamericana - Dictadura Universidad - Reforma - Política

\section{ABSTRACT}

In this article we propose to analyze the orientation of the university policy during the last dictatorship in Argentina (1976-1983). We focus on its position on the University Reform of 1918 and its inheritance, as it was one of the main axes of diagnosis and intervention and despite this fact, this is a little studied aspect. We address the discourses of educational authorities at the national level and the supervisors of the University of Buenos Aires (UBA), the country's main higher education institution. Likewise, we describe the application of the dictatorial university policy by giving an account of the transformations that they sought to impose. Finally, we reconstruct some of the conflicts and disputes that took place among the university actors in Buenos Aires about the implemented policy.

In conclusion, we propose the anti-reform orientation of the dictatorial university policy developed in the UBA, which was fundamentally against two pillars: co-government and university autonomy. However, we state that despite the objectives proposed by the regime, the student movement recovered this tradition at the end of the dictatorial period. To carry out this study we resort to a methodological strategy of triangulation of primary sources of diverse character (ministerial documentation, materials of the Armed Forces, university regulations, speeches of authorities, press releases) and secondary ones.

Keywords: Journal History of Latin American Education; dictatorship; university; Reform-Policy.

\section{RESUMO}

No presente artigo nos propusemos a analisar a orientação da política universitária da última ditadura na Argentina (1976-1983). Nos concentramos em seu posicionamento a respeito da Reforma Universitária de 1918 e sua herança, pois foi um de seus principais eixos de seus diagnósticos de intervenção e é um aspecto que permaneceu pouco estudado. Abordamos os discursos das autoridades educativas em nível nacional e os reitores interventores da Universidade de Buenos Aires (UBA), principal casa de altos estudos do país.

Da mesma forma, descrevemos a aplicação da política universitária ditatorial na dita instituição, dando conta das transformações que buscavam se impor. Por último, reconstituímos alguns dos conflitos e disputas que tiveram lugar entre os atores universitários de Buenos Aires sobre a política implementada.

Como conclusão, propomos a orientação antirreformista da política universitária ditatorial desenvolvida na UBA, fundamentalmente contra dois de seus pilares: o co-governo e a autonomia universitária. Todavia, sustentamos que apesar dos objetivos propostos pelo regime, o movimento estudantil recuperou essa tradição no final da etapa ditatorial.

Para desenvolver este trabalho recorremos a uma estratégia metodológica de triangulação de fontes primárias de caráter diverso (documentação ministerial, materiais das Forças Armadas, normativa universitária, discursos de autoridades, notas jornalísticas) e secundárias.

Palavras-chave: Revista História da Educação Latino-americana; Ditadura; Universidade; Reforma - Política. 


\section{INTRODUCCIÓN}

La historia de las universidades nacionales (en adelante UUNN) en Argentina durante el siglo XX conoció sin duda un momento fundamental durante los sucesos de la Reforma Universitaria de 1918 que tuvo lugar en los claustros de la Universidad Nacional de Córdoba. ${ }^{3}$ La extensión de sus principios más importantes (autonomía universitaria, administración y gobierno de las casas de estudio por los miembros de sus comunidades académicas -docentes, graduados y estudiantes-, concursos públicos para acceder a los cargos docentes, entre otros) al resto de las casas de estudio del país y del continente fue dispar y a través de procesos más o menos conflictivos. ${ }^{4}$

Pocos años después del establecimiento de los estatutos reformistas, se dieron procesos denominados "contra-reformistas" que limitaron o dieron marcha atrás con los cambios precedentes. Los sectores opositores al orden reformista se consolidaron al interior de los claustros a partir del golpe encabezado por el general José Felix Uriburu en 1930, el primero de numerosas incursiones militares en el poder ejecutivo. ${ }^{5}$ Así, las principales casas de estudio superiores fueron intervenidas.

Desde entonces, la vida política de las UUNN se ha visto conmocionada directamente por los cambios que tuvieron lugar a nivel del estado nacional. A grandes rasgos, con cada nuevo golpe de estado, fueron designadas autoridades no electas por la comunidad académica y los sectores opositores al régimen de turno fueron perseguidos. Entre los procesos de intervención deben destacarse los de 1946-1955, 1966-1973 y 1976-1983. Los tres se iniciaron con un golpe de estado militar, en el caso del primero continuó bajo la injerencia del gobierno peronista democráticamente electo, y los otros dos casos corresponden a gobiernos de facto controlados por las Fuerzas Armadas (FFAA en adelante). Durante esos años, se despidieron docentes e investigadores, se suspendió la actividad política de los centros y federaciones estudiantiles, así como el funcionamiento de los gobiernos universitarios.

La Universidad de Buenos Aires (UBA en adelante), particularmente, permaneció intervenida por el estado nacional desde junio de 1966 hasta marzo de 1986 cuando, bajo un régimen democráticamente electo, se volvió a reunir la Asamblea Universitaria para elegir autoridades. La Federación Universitaria de

3 Cf. Pablo Buchbinder, ¿¿Revolución en los claustros? La Reforma Universitaria de 1918 (Buenos Aires: Sudamericana, 2008).

4 Pablo Buchbinder, Historia de las universidades argentinas (Buenos Aires: Sudamericana, 2010); Hugo Biagini, "La cultura de la resistencia juvenil y el proceso emancipador", RHELA, No. 11 (2008); Andrés Donoso Romo, "Constantes en los movimientos estudiantiles latinoamericanos: aproximación a partir del caso chileno de 2011”, RHELA 19; No. 28 (2017).

5 Golpes de estado en Argentina durante el siglo XX: Uriburu gobernó entre 1930 y 1932, iniciando la llamada "década infame" por el tipo de democracia fraudulenta que se desarrolló; entre 1943 y 1946 gobernaron de facto los generales Pedro Ramírez y Edelmiro Farrell. En 1955, la segunda presidencia de Juan Domingo Perón fue interrumpida por el golpe militar autodenominado como "Revolución Libertadora" que gobernó hasta 1958. En 1966, tuvo lugar una nueva interrupción al régimen democrático con la autoproclamada "Revolución Argentina", esta vez instaurando la "dictadura burocrática autoritaria" de las FFAA hasta mayo de 1973. Finalmente, en marzo de 1976, tuvo lugar el último golpe de estado de la historia nacional dando lugar al autodenominado "Proceso de Reorganización Nacional" hasta diciembre de 1973. Cf. William, Daros, "Incidencias del proceso histórico en el proceso educativo argentino", RHELA 16, No. 22 (2014); Laura Rodríguez, "Los ministros de educación en Argentina (1854-2015): análisis de los perfiles profesionales de las élites políticas”, História da Educação 21, No. 51 (2017). 
Buenos Aires (FUBA), con sus banderas reformistas, se constituyó como uno de los principales actores que presentaron su oposición a las intervenciones y a las dictaduras de turno. ${ }^{6}$

De modo muy sintético hemos descrito una historia universitaria en Argentina de carácter irregular, donde la herencia reformista fue cuestionada sucesivamente. Sin embargo, su tradición fue rescatada para proponer un modelo universitario contrario a la injerencia directa del gobierno de turno en la vida académica y política de los claustros. A punto de cumplirse el centenario de la Reforma Universitaria, en este texto procuramos profundizar sobre las valoraciones que las autoridades de la última dictadura cívico-militar en Argentina construyeron acerca de la misma. Asimismo, analizamos de qué modo y en qué medida dichas ideas orientaron las políticas implementadas en la principal casa de altos estudios del país. Así, con este trabajo, nos proponemos aportar a la comprensión de la importancia histórica de este fenómeno universitario en la historia reciente: ¿Por qué la dictadura quería erradicar su influencia?, ¿Qué modelo universitario proponía en cambio?

Con este horizonte, abordamos los discursos de las autoridades educativas a nivel nacional y los rectores interventores de la UBA y describimos algunas de las medidas desarrolladas en dicha institución, dando cuenta de las transformaciones que buscaban imponerse. Por último, reconstruimos conflictos y disputas que tuvieron lugar entre los actores universitarios de Buenos Aires sobre la política implementada.

El texto se organiza en tres apartados. En el primero abordamos los diagnósticos acerca de la realidad universitaria elaborados por las autoridades educativas y universitarias de la última dictadura. A continuación, analizamos los principales rasgos de la universidad anti-reformista que buscaron construir desde el Ministerio, y las tensiones que en relación con dicho proyecto surgieron entre las autoridades porteñas y las nacionales. En el tercer apartado planteamos algunas consideraciones acerca de la recuperación de la tradición reformista por parte del movimiento estudiantil contra la dictadura. Finalizamos el texto planteando algunas reflexiones transitorias sobre el proceso analizado.

Vale destacar que en este trabajo recurrimos a una estrategia metodológica de triangulación de fuentes primarias de diverso carácter (documentación ministerial, materiales de las Fuerzas Armadas, normativa universitaria, discursos de autoridades, notas periodísticas) y secundarias.

\section{Un diagnóstico específico para el "problema universitario"}

El golpe de estado del 24 de marzo de 1976 instaló en Argentina el denominado "Estado Terrorista" (Duhalde, 2013), caracterizado por la militarización del aparato del estado y un alto contenido represivo que pretendió la aniquila-

6 Cf. Juan Califa, Reforma y revolución. La radicalización política del movimiento estudiantil de la UBA 1943-1966 (Buenos Aires: EUDEBA, 2014); Guadalupe Seia, "Militancia, oposición y resistencia estudiantil en la Universidad de Buenos Aires durante la etapa final de la última dictadura (1981-1983)”, Historia, voces y memoria, No. 9 (2016). 
ción física de sus opositores y el amedrentamiento de la población a través del terror. El dispositivo represivo incluyó el secuestro, la tortura y la desaparición sistemática de personas así como el funcionamiento de centros clandestinos de detención. La universidad fue uno de los terrenos donde la represión paraestatal y estatal se asentó. Esto se hace observable en el hecho de su inmediata intervención y en que al finalizar la etapa, más del 20\% de los desaparecidos fueron estudiantes (Comisión Nacional sobre la Desaparición de Personas).

Entre 1976 y 1983, el Ministerio de Cultura y Educación (MCE en adelante) fue gestionado, luego del breve paso del Contralmirante Guzzetti, por cinco ministros civiles y por el Ministro del Interior. ${ }^{7}$ Del mismo modo que en términos generales los actores protagónicos del denominado "Proceso de Reorganización Nacional" ("PRN" en adelante) no compartían proyectos económicos y políticos para el país pero lograban cohesión a partir del objetivo común de desarrollar la denominada "lucha antisubversiva" ${ }^{8}$, en materia educativa numerosos especialistas han destacado que el conjunto de los funcionarios de la mencionada cartera no compartían un único proyecto educativo y de universidad. Sin embargo, existía acuerdo respecto de la necesidad de eliminar los "elementos disruptivos" del orden de los claustros, que amenazaban a la nación toda. ${ }^{9}$

Novaro y Palermo han afirmado que luego del ámbito sindical, el segundo frente en orden de importancia para la represión fue el educativo y, en particular, la universidad. ${ }^{10}$ Desde el mismo momento del golpe, las agrupaciones estudiantiles fueron identificadas como "enemigas activas" y perseguidas sistemáticamente. El objetivo era erradicar definitivamente de este espacio la acción "disolvente" de los "elementos subversivos" y cualquier vínculo con la universidad movilizada de fines de la década de 1960 y principios de 1970. Esto se llevó a cabo a través de la represión, el disciplinamiento y el reordenamiento de las casas de estudios. ${ }^{11}$

Las acciones desarrolladas desde las FFAA y el MCE en el ámbito universitario se asentaban en un diagnóstico compartido: el ámbito educativo había sido el

7 Ricardo Bruera (marzo 1976-mayo 1977), Gral. Álvaro Harguindeguy (mayo-junio 1977 y agosto-noviembre 1978), José Catalán (junio 1977-agosto 1978), Juan Llerena Amadeo (noviembre 1978-marzo 1981), Carlos Burundarena (marzo-diciembre 1981) y Cayetano Licciardo (diciembre 1981-diciembre 1983). Los ministros civiles tenían en común entre sí su relación directa con el ámbito universitario (egresados y profesores) y su vinculación con círculos católicos tradicionales y jerárquicos de la Argentina. Asimismo, todos ellos habían ocupado cargos durante la "Revolución Argentina". Sobre las trayectorias de los ministros ver Laura Rodríguez, Católicos, nacionalistas y políticas educativas durante la última dictadura (1976-1983) (Rosario: Prohistoria, 2001); Laura Rodríguez, Universidad, peronismo y dictadura. 1973-1983 (Buenos Aires: Prometeo, 2015).

8 Paula Canelo, El proceso en su laberinto. La interna militar de Videla a Bignone (Buenos Aires: Prometeo, 2009).

9 Carolina Kaufamnn (dir.), Dictadura y Educación (1976-1983), Tomos I y II (Buenos Aires, Miño y Dávila, 2001 y 2003); Gabriela Águila, "La Universidad Nacional de Rosario en dictadura (1976-1983): depuración, "normalización" y reestructuración institucional", PolHis, Año 7, No. 14 (2015); Laura Rodríguez y Germán Soprano, "La política universitaria de la dictadura militar en la Argentina: proyectos de reestructuración del sistema de educación superior (1976-1983)”, Nuevo Mundo, Mundos Nuevos (2009); Víctor Algañaraz Soria, "Reestructuración universitaria en clave autoritaria: política y accionar de los rectores de la Universidad Nacional de San Juan durante la última dictadura militar (1976-1983)”, PolHis, Año 7, No. 14 (2015); Rodríguez, Laura, Universidad, peronismo y dictadura. 1973-1983, op. cit.; entre otros.

10 Marcos Novaro y Vicente Palermo, La dictadura militar. (1976- 1983). Del golpe de Estado a la restauración democrática (Buenos Aires: Paidós, 2003).

11 Pablo Buchbinder, Historia de las universidades argentinas, op.cit.; Guadalupe Seia, "La Universidad de Buenos Aires (UBA) entre la "Misión Ivanissevich" y la última dictadura (1974-1983). Represión, "reordenamiento" y reconfiguraciones de la vida estudiantil", (Tesis de Maestría en Historia Contemporánea en, IDH-UNGS, 2016). 
objetivo fundamental de las "corrientes ideológicas subversivas". ${ }^{12}$ El problema "más grave" se localizaba en la universidad debido a la edad del estudiantado y la trascendencia política de la actividad. Allí, seleccionaban entre los estudiantes cuadros políticos, gremiales y militares para desarrollar una "guerra total contra la República" y además, provocaban confusión y desorientación política e ideológica en la juventud. ${ }^{13}$

El origen de la penetración del "enemigo subversivo" en la universidad fue identificado por las autoridades del "PRN" en la Reforma de 1918 que había sido influenciada por la Revolución Bolchevique de $1917 .{ }^{14}$ A partir de entonces, los jóvenes estudiantes habían comenzado a movilizarse y politizarse, pensando que incluso podían y "debían” tener injerencia en el gobierno de las casas de altos estudios. Desde 1955, la Federación Universitaria Argentina (FUA en adelante) infiltrada por los comunistas "copó la universidad" y logró su objetivo principal: el co-gobierno tripartito. Asimismo, con la aplicación de la ley universitaria de 1958, tuvieron lugar los concursos que posibilitaron que profesores formados en el exterior que eran "dirigentes marxistas" accedieran a las cátedras. ${ }^{15}$

En 1966, con la toma del poder por parte de Juan Carlos Onganía y la instauración de una dictadura autodenominada como "Revolución Argentina", las UUNN fueron intervenidas. De este modo, se procedió al desplazamiento de algunos de los docentes "marxistas" y se puso fin al co-gobierno y la autonomía universitaria. Sin embargo, no lograron contener a los estudiantes "izquierdistas" que continuaron movilizándose. En efecto, el movimiento estudiantil fue uno de los protagonistas de las movilizaciones de masas que tuvieron lugar en diferentes ciudades argentinas entre 1969 y 1972. En 1973, con el triunfo electoral de los candidatos de identidad peronista, sostenían desde el "PRN", regresaron a los claustros dichos docentes, produciendo "la destrucción más intensa que se conoce de la Universidad, y el desarrollo del proceso de captación de jóvenes para integrar los cuadros del terrorismo $(. . .)^{\prime \prime} .^{16}$

Según estos documentos, entre 1973 y 1975 “el terrorismo en el poder" había actuado en el área educativa a través del personal jerárquico, docente y no-docente de las instituciones junto con las organizaciones estudiantiles y gremiales de los trabajadores educativos, quienes habían difundido de diversos modos la "ideología marxista". Asimismo se había utilizado bibliografía, material de enseñanza y recursos didácticos "transmisores objetiva o subjetivamente" de dicha tradición.

12 Fuerzas Armadas (FFAA), "El Terrorismo en Argentina” (Buenos Aires, 1979). También Cf. Ministerio de Cultura y Educación (MCE), Subversión en el ámbito educativo. Conozcamos a nuestro enemigo (Buenos Aires, 1977); Estado Mayor General del Ejército, Marxismo y Subversión. Ámbito educacional (Buenos Aires, 1980); Gustavo Landívar, La Universidad de la Violencia (Buenos Aires: Ediciones de Palma, 1980).

13 "El Terrorismo en Argentina", op. cit., (cita 12).

14 "Subversión en el..., op. cit., (cita 12).

15 Cf. Pablo Buchbinder, "Ley 14.557" en La Universidad en los debates parlamentarios, eds. Pablo Buchbinder (Los Polvorines: UNGS, 2014).

16 "El Terrorismo en Argentina", op. cit., (cita 12). 
Respecto de las agrupaciones estudiantiles ${ }^{17}$, desde las FFAA describían su accionar: en primer lugar, ofrecían charlas individuales sobre reclamos específicos como "comedor para los estudiantes, bibliotecas, actitudes excesivamente rigurosas de algún profesor, autonomía universitaria y/o ingreso irrestricto". Aquellos alumnos que "aceptan de buena fe" esas ideas se encontraban "listos" para el desplazamiento argumental hacia otros contenidos como "la universidad debe ser para los alumnos, su gobierno corresponde a los estudiantes, o por lo menos ha de ser tripartito, la universidad no debe ser solo para los hijos de los ricos, las injusticias sociales". ${ }^{18}$ Se observa la identificación de las banderas de la Reforma Universitaria como contenidos para el "adoctrinamiento subversivo" de los y las jóvenes. La última etapa consistía, sostenían, en la promoción de slogans que llamaban a la "acción directa". Para los funcionarios del régimen, una vez que el estudiante era "convenientemente motivado", perdía "su condición de tal, pues se lo sacaba de la universidad para pegar carteles en la ciudad, realizar contactos de tipo terrorista $(. . .)^{\prime \prime}{ }^{19}$.

Según este diagnóstico, el accionar desde las instituciones de los mencionados "sectores marxistas" coincidió con el "movimiento de agitación estudiantil dirigido y capitalizado por las organizaciones terroristas". Las mismas "estrangularon" todo intento de enseñar y aprender en las UUNN. Por un lado, avasallaron la "libertad de enseñar" a través de "juicios 'académicos' por 'tribunales populares'" que decretaban la expulsión "sin posibilidad de defensa" o impulsaban "renuncias forzosas". Por otro, el "derecho a aprender" del alumnado se vio limitado por "la agitación, asambleas digitadas y tumultuarias, huelgas, ocupaciones de facultades e Institutos, tiroteos y otras manifestaciones" ${ }^{20}$

Se observa que el "problema universitario" quedó subsumido al problema político-ideológico de la lucha contra la "subversión" en el ámbito de las UUNN. En el diagnóstico de la dictadura, la raíz del problema estaba en la herencia del Reformismo de 1918 que estimulaba a los jóvenes a politizarse y organizarse para formar parte del gobierno universitario. Para "neutralizar el accionar subversivo y reconstruir la Nación", se procedió a restaurar "el orden imprescindible para enseñar y aprender en paz", mediante la acción de los delegados de las FFAA y la colaboración de "civiles con alto prestigio académico". ${ }^{21}$

La UBA fue intervenida en marzo de 1976 quedando bajo el control del Capitán de Navío Edmundo Said. A los pocos meses, en agosto de ese año, se inició la etapa de gestiones a cargo de civiles pero con la designación y el control perma-

17 Tanto "El Terrorismo en Argentina" como "Marxismo y Subversión. Ámbito educacional" incluyen un detallado mapa de las diferentes agrupaciones estudiantiles, su vinculación con partidos y organizaciones revolucionarias, su tendencia ideológica y las principales características de su accionar. Asimismo, "El terrorismo..." y el citado libro de Landívar contienen un detallado listado de eventos y acciones "terroristas" perpetradas en los claustros o según sostienen por organizaciones "subversivas" pertenecientes al ámbito universitario.

18 "El Terrorismo en Argentina", op. cit., (cita 12).

19 Ibídem.

20 Ibídem.

21 Idem. 
nente del MCE y el Poder Ejecutivo Nacional (PEN en adelante). ${ }^{22}$ El delegado militar condujo la "limpieza de los claustros", procedió a "cesar en funciones" al personal docente y no docente. Más de 150 investigadores, profesores, auxiliares y preceptores fueron separados de sus cargos en todas las unidades dependientes de la UBA durante los meses de la gestión de Said. ${ }^{23}$

Para los estudiantes se volvió norma la exigencia para la inscripción de un certificado de domicilio actualizado expedido por la Policía Federal y un certificado de buena conducta o antecedentes penales. Esto se combinó con la presencia constante de las fuerzas represivas en las instalaciones de toda la UBA. Los controles en los ingresos de las unidades académicas por parte de personal uniformado, en ocasiones "armados con fusiles enormes", no se interrumpieron hasta el final de la etapa. Asimismo, en todas las facultades había pequeñas "comisarías" de la Policía Federal. También, numerosos testimonios retratan la presencia de agentes "de civil". Los mismos realizaban trabajos de inteligencia y hacían un seguimiento de ciertos estudiantes. ${ }^{24}$ En lo que respecta a las víctimas de la represión en la UBA, las cifras disponibles hasta el momento indican que hubo 636 desapariciones. ${ }^{25}$

\section{Contra la herencia reformista}

\section{Por una comunidad jerárquica y desmovilizada}

A partir de los diagnósticos de las autoridades educativas, el sistema universitario debía ser "aseado", "reordenado" y "redimensionado". ${ }^{26}$ El proceso de reorganización se orientó para revertir los pilares fundamentales de la herencia reformista: el co-gobierno y la autonomía universitarios. Como veremos en adelante, el primero de estos puntos concentró un acuerdo casi unánime, mientras

22 Desde ese momento hasta fines de 1983, las máximas autoridades fueron: Alberto Constantini (agosto 1976-septiembre 1976), Libertario Rabasa (septiembre 1976-febrero 1977), Luis Cabral (febrero 1977-agosto 1978), Alberto Donnes (agosto 1978-noviembre 1978), Lucas Lennon (noviembre 1978-noviembre 1981), Alberto Rodríguez Varela (diciembre 1981-diciembre 1982) y Carlos Segovia Fernández (diciembre 1982- diciembre 1983). Estos actores civiles poseían una trayectoria en el sistema de educación superior y en la propia casa de estudio porteña. Eran parte de los equipos docentes de las facultades y varios se habían desempeñado como decanos, fundamentalmente durante la intervención de la dictadura anterior. Sobre cada una de sus trayectorias ver Guadalupe Seia, "Rectores de la Universidad de Buenos Aires entre 1974 y 1983: curricula vitae, discursos y comunicados de prensa. Estudio preliminar", Cuaderno 5, Programa Historia y Memoria (Buenos Aires: UBA, 2014).

23 Resoluciones $\mathrm{N}^{\circ}$ 71-77; 85-89; 97-103; 113-115 (04/1976); 139-140, 142, 147 (30/04/1976); 162 (04/05/1976); 180 (05/05/1976); 185187 (07/05/1976); 194 (11/05/1976); 222 (12/95/1976); 224 (17/05/1976); 233 (17/05/1976); 279 (27/05/1976); 360 (31/05/1976); 376, 377, 383 (07/06/1976); 401-413 (11/06/1976); 422 (15/06/1976); 226 (16/06/1976); 455 (23/06/1976); 466 (25/06/1976); 474 (28/06/1976); 502 (02/07/1976); 503, 505 (05/07/1976); 517 (06/07/1976); 530 (12/07/1976); 602-604 (22/07/1976); 636, 638 (28/07/1976); 648 (30/07/1976); entre otras, Rectorado de la UBA, Buenos Aires.

24 Juan Pablo Paz (estudiante en FCEN y militante de la Federación Juvenil Comunista) recuerda que durante el interrogatorio que le hicieron luego de ser detenido en Ciudad Universitaria le mostraron un conjunto de fichas escritas a mano con datos sobre su vida personal, académica y política en la facultad. Entrevista a Paz, Juan Pablo, Buenos Aires, 26 de mayo de 2015.

25 También se conoce que hubo 130 desaparecidos vinculados a la Facultad de Arquitectura, 27 de la carrera de Psicología, 72 de la Facultad de Ciencias Económicas, 70 desaparecidos de la Facultad de Ciencias Exactas y Naturales y 127 víctimas de la Facultad de Filosofía y Letras. Guadalupe Seia, "La Universidad de Buenos Aires (UBA) entre la "Misión Ivanissevich" y la última dictadura (1974-1983)..., op. cit., (cita 11).

26 En el presente texto no focalizaremos sobre la faceta represiva ni la política de "redimensionamiento" desarrolladas por la última dictadura a nivel universitario. Cf. Guadalupe Seia, "La Universidad de Buenos Aires (UBA) entre la "Misión Ivanissevich" y la última dictadura (1974-1983)..., op. cit., (cita 11). 
que la cuestión de la autonomía suscitó debates y tensiones entre las autoridades universitarias y las del PEN durante los primeros años de la intervención militar.

$\mathrm{El}$ "reordenamiento universitario" propuesto desde la cartera educativa buscaba transformar la estructura de gobierno y funcionamiento de la institución. En este sentido, el co-gobierno tripartito (igualitario o no), en tanto auto-gobierno de la institución con participación estudiantil, era una amenaza concreta ya que estimulaba la injerencia en las decisiones del estudiantado y con ello, su politización, movilización e "izquierdización".

La ley $\mathrm{N}^{\circ} 21.276$ "Prioridad para la normalización de las universidades nacionales" (1976) dispuso que el gobierno, la administración y la designación de autoridades de las universidades fueran ejercidos por el MCE. También quedaba facultado para resolver las situaciones "que afecten la paz, el orden interno de las universidades y su funcionamiento normal" (Art. 4) no previstas en esta ley y para disponer del cese del personal docente y directivo (Art. 10). Continuaba prohibida toda actividad de "adoctrinamiento, propaganda, proselitismo o agitación de carácter político o gremial" (Art. 7). Estas disposiciones continuaron presentes (artículos 4, 57, 34, 39, 74) en la ley № 22.207 sancionada en 1980.

Las autoridades educativas y las de la UBA rechazaron la posibilidad de que la universidad fuese gobernada por profesores y alumnos. El primer rector civil de la etapa Alberto Constantini que como veremos insistió en la necesidad de un gobierno autónomo de las universidades, sostenía que la modalidad tripartita era "una razón de desórdenes". Para el ingeniero, el gobierno de la casa de estudio debía ser normado en términos académicos y así dar expresión a los claustros para la "búsqueda mancomunada" de la solución a los "grandes problemas" de la universidad..$^{27}$ Los estudiantes podrían participar, al igual que los graduados, en una proporción minoritaria. Para ello, se establecerían condiciones de idoneidad (calificaciones), evitando que el cargo de delegado estudiantil fuera utilizado con una función política. Por otro lado, afirmaba que no había que negar el pensamiento político del alumnado "siempre y cuando no se desarrolle dentro del ámbito universitario". En cambio, quienes esgrimieran "argumentos para destruir nuestro estilo de vida" debían ser desterrados de la universidad y del país. El objetivo era una universidad que borrara "definitivamente esa imagen politizada y conflictiva" ${ }^{28}$

El enfrentamiento a la "universidad reformista" cuestionaba de raíz la existencia de un demos universitario constituido por los estudiantes y que ellos tuvieran la posibilidad de participar igualitariamente en el gobierno de la institución. En tal sentido, el Sub-secretario de Educación, Eduardo Ventura afirmaba en referencia a la tradición reformista: "Queremos una Universidad y no un soviet tumultuoso de profesores, alumnos y egresados" ${ }^{29} \mathrm{El}$ orden en el interior de

27 "Palabras del rector de la UBA en la Carrera de Psicología" (Buenos Aires, 11/08/1976), Archivo Histórico de la Universidad de Buenos Aires, A. Constantini.

28 "Palabras del rector de la UBA en la Facultad de Agronomía" (Buenos Aires, 11/08/1976), Archivo Histórico de la UBA, Buenos Aires, A. Constantini.

29 Anónimo, "La pelea por la nueva Universidad", Confirmado, Buenos Aires, julio, 1979, 14-18. 
los claustros de la UBA debía ser jerárquico (y cristiano, occidental y patriótico), bajo la orientación del gobierno nacional y del MCE. Estos criterios y orientaciones primaron también en el ordenamiento para la universidad sancionado en 1980. Allí se dispuso que la Asamblea Universitaria, Consejos Superiores y Académicos estarían integrados exclusivamente por las autoridades designadas por el PEN y por un número reducido de profesores elegidos por voto obligatorio y secreto de los profesores regulares de cada facultad. Por otra parte, dichas funciones jerárquicas en la universidad eran incompatibles con cargos político-partidarios o gremiales.

Los rectores porteños acordaban en el papel subordinado que los estudiantes ocupaban en la jerarquía universitaria. Si bien debían ser escuchados, no podían formar parte del gobierno universitario, incluso a pesar de estar formándose para desempeñarse como "ciudadanos y profesionales de la República".

A partir de 1978, desde la Secretaría de Asuntos Estudiantiles del Rectorado y de las diferentes facultades, se promovió el contacto entre las autoridades y los alumnos para recoger sus inquietudes y problemáticas. ${ }^{30} \mathrm{El}$ rector Lucas Lennon desarrolló una política activa de acercamiento y diálogo con los alumnos. Se organizaron encuentros entre el rector e ingresantes y estudiantes de cada facultad (aquellos con los mejores promedios). ${ }^{31}$ Afirmaba que era sumamente importante el "diálogo" con los jóvenes estudiantes (los "alumnos distinguidos") para que ellos acercaran sus pareceres, preocupaciones, molestias y demás cuestiones que para el estamento estudiantil pudieran ser relevantes. Sostenía la necesidad de tener esas conversaciones "respetuosas, responsables y amables" como parte fundamental de su política en la UBA.

Este diálogo, por supuesto, no significaba efectiva participación política, los estudiantes ocupaban un rol de discípulos en la comunidad jerarquizada que era la universidad para las autoridades del momento. Para el mismo rector, la juventud era el principal "destinatario" de la obra que estaban desarrollando. Los objetivos de la educación superior solo se lograrían con "orden" fruto de "la convivencia armónica y respetuosa de los diferentes estamentos que componen la comunidad universitaria, por esencia jerarquizada" donde los docentes forman y los estudiantes "reciben" el conocimiento. ${ }^{32}$ Se postuló una idea de estudiante "apolítico" y, sobretodo, que no se movilizara para modificar alguna situación, tampoco para manifestar apoyo a las autoridades. "La política" (el cogobierno, la actividad de las agrupaciones estudiantiles, la actividad gremial

30 Resolución UBA Nº372 (04/06/1976); Archivo Histórico de la UBA, Rectorado, Memorias de la Universidad de Buenos Aires, (Buenos Aires, 1979-1982).

31 "Palabras del rector L. Lennon con los alumnos de Agronomía”, (Buenos Aires, 25/05/1979); "Palabras del rector con estudiantes de Odontología, (05/06/19798); "Palabras del rector Lennon de la UBA" (10/5/1979); "Recepción de abanderados y escoltas de facultades y carreras" (10/5/1979); "Palabras del rector con estudiantes de Arquitectura”, (22/06/1979); "Palabras del rector Lennon en la reunión con alumnos de la Facultad de Ciencias Económicas", (24/10/1979). Archivo Histórico de la UBA, Dirección de Prensa y Difusión "18 alumnos ingresantes se reunieron con el rector de la UBA, (Buenos Aires, 21/05/1980); "Recibió el rector de la UBA a alumnos ingresantes altamente calificados", (06/05/1981); "Palabras del rector en la reunión de participación estudiantil”, (Buenos Aires, 02/06/1981), Archivo Histórico de la UBA, Buenos Aires.

32 “Palabras del rector de la UBA, Dr. Lennon. Recepción de abanderados y escoltas de facultades y carreras", (Buenos Aires, 10/5/1979), Archivo Histórico de la UBA. 
de los trabajadores e incluso la actividad partidaria de los docentes) continuó siendo considerada como la causante de los conflictos y los desórdenes institucionales. Lennon sostenía que los estudiantes no debían participar del gobierno pero sí de la vida universitaria.

Esta perspectiva compartida también se cristalizó en la nueva ley universitaria en el artículo 36. El nuevo estatuto de la UBA (aprobado por el PEN en 1981) reglamentó que en cada facultad debían organizarse dependencias para promover la "participación estudiantil" de modo de prepararlos para su "integración responsable en la comunidad nacional". Así, se lograría orientar "sus aptitudes culturales, sociales y cívicas" a partir de actividades artísticas, deportivas y recreativas. Estas dependencias, además, debían posibilitar la canalización de las inquietudes, sugerencias y peticiones de los alumnos, y funcionar como instancias de información de aquellos asuntos estudiantiles tales como orientación vocacional, ayudas económicas, bolsas de trabajo, etc. ${ }^{33}$ La participación que tenían permitida los estudiantes era estrictamente recreativa y, exclusivamente, por los medios y espacios organizados y controlados por las autoridades.

En ese marco, se destacó el impulso y el respaldo de los decanatos para la creación de revistas o gacetillas estudiantiles. En general, estas experiencias se concentraron durante los últimos años de la etapa dictatorial cuando comenzaban a circular mayor cantidad de materiales elaborados por estudiantes y agrupaciones estudiantiles que no apoyaban la intervención..$^{34}$ Las autoridades sostenían que con estos espacios y la producción de materiales se buscaba incrementar la comunicación entre el alumnado y las autoridades. ${ }^{35}$ En las Ciencias Exactas, este boletín era elaborado desde el Ârea de Cultura de la Secretaría con participación estudiantil y contenía notas científicas, de divulgación, de historia, de interés general e informaciones sobre las actividades de la facultad y la universidad..$^{36}$

En Ciencias Económicas encontramos una expresión más temprana, con constancia y efectos trascendentes en la vida estudiantil. En noviembre de 1980 se publicó el primer número de la revista estudiantil Base $\mathrm{Cero}^{37}$, contando entre otras notas con unas palabras de estímulo a la iniciativa del propio decano Licciardo (quien participó con colaboraciones escritas en otros números también). La revista, vale destacar, también contaba con la adhesión del Colegio de Graduados y del Consejo Profesional de Ciencias Económicas. Mientras que su

33 Resolución No. 429, Anexo I, Art. 99, (Buenos Aires, 01/09/1981), Rectorado de la UBA.

34 Cf. Guadalupe Seia, "Las Revistas Estudiantiles en la Universidad de Buenos Aires durante la última dictadura (1976-1983). Un estudio exploratorio sobre las prácticas culturales del estudiantado universitario en la Facultad de Ciencias Exactas y Naturales", (Ponencia presentada en el "I Coloquio de Historia de las Juventudes, La Condición Juvenil en América Latina", Ciudad de México: UNAM, 2017); Guadalupe Seia, "El movimiento estudiantil de la Universidad de Buenos Aires (UBA) entre la Guerra de Malvinas y la salida democrática (1982-1983). Un estudio de caso sobre la Facultad de Ciencias Exactas y Naturales (FCEN)", (Ponencia presentada en el "IX Seminario Internacional Políticas de la Memoria", Buenos Aires: Centro Cultural de la Memoria Haroldo Conti, 2016).

35 “Memorias de la UBA. Año 1981", (Buenos Aires, 1982), Rectorado, Archivo Histórico de la UBA.

36 "Memorias de la UBA. Año 1982", (Buenos Aires, 1983), Rectorado, Archivo Histórico de la UBA. Desafortunadamente, no hemos accedido a esas gacetillas y boletines elaborados desde la Secretaría de Asuntos Estudiantiles por lo cual no podemos ahondar nuestro análisis ni avanzar hacia una perspectiva comparativa en relación con las revistas estudiantiles de dicha facultad.

37 En la Biblioteca de la Facultad de Ciencias Económicas se encuentran para la consulta los siguientes números: 1 (noviembre de 1980); 2 (mayo de 1981); 3 (septiembre de 1981); 4 (diciembre de 1981); 6 (noviembre de 1982). 
cuerpo de redacción se componía por estudiantes de las carreras de la facultad, su Cuerpo Asesor estaba integrado por cuatro docentes de la casa que tenían funciones de gestión también. Cada edición (seis números hasta diciembre de 1982) contenía notas sobre temáticas de economía, administración y contaduría, tanto teóricas como de coyuntura. En general las mismas eran escritas por docentes y profesionales del área, pero también había materiales elaborados por estudiantes, fundamentalmente entrevistas. En esa sección, sobresalieron las notas al Ministro de Educación Burundarena; el Secretario de Asuntos Estudiantiles de la universidad; al coordinador del Departamento de Cultura de la Facultad; a periodistas de los principales medios de comunicación a nivel nacional; a economistas destacados; al presidente del Colegio de Graduados, entre otros. También había sección cultural, de humor y deportiva, así como también espacios que retrataban e ironizaban sobre los rasgos de la vida universitaria de dicha facultad. Asimismo, se informaba sobre diversas reglamentaciones administrativas, tales como las condiciones de ingreso para cada año y del arancelamiento de los cursos, actividades académicas y culturales, etc. A lo largo de los números, se fueron planteando como el espacio para la participación estudiantil, para acercarle propuestas y problemáticas para que las autoridades solucionen, contraponiéndose a la militancia estudiantil de los años setenta.

Este fenómeno es de suma relevancia, sobre todo si consideramos que la elaboración de revistas por parte de los estudiantes fue una de las iniciativas "desde abajo" más relevante en las facultades hasta una mayor rearticulación del movimiento estudiantil a partir de la Guerra de Malvinas (primer semestre de 1982). Las autoridades crearon espacios de expresión estudiantil coordinados y orientados por ellas para contrarrestar las actividades de los estudiantes que tempranamente (1978) comenzaban a reunirse para hacer lo propio de manera independiente, clandestina e ilegal. Vale destacar que a pesar de la aparición de esos materiales oficiales, las revistas estudiantiles continuaron siendo elaboradas y difundidas.

Las autoridades universitarias también fomentaron espacios de recreación estudiantil para la realización de actividades culturales y la práctica deportiva. Estos elementos eran considerados centrales para la "formación humanista integral" de los jóvenes estudiantes. Respecto de las actividades culturales, las Memorias de la universidad describen una cantidad no despreciable de eventos, actuaciones, talleres sobre diferentes disciplinas, cursos de idiomas, muestras, concierto, conformaciones de coro y grupos de teatro por facultad que tuvieron lugar en las diferentes facultades y escuelas dependientes del rectorado. ${ }^{38}$

El estímulo del deporte también tomó relevancia en el contexto de una política tendiente a lograr el "desarrollo armonioso y pleno de la personalidad y el ca-

38 "Memorias de la Universidad de Buenos Aires", (Buenos Aires, 1979-1982), Rectorado, Archivo Histórico de la UBA. 
rácter". ${ }^{39}$ Laura Luciani ${ }^{40}$ ha señalado la importancia de la práctica deportiva en el ideal de juventud que proponían las FFAA. Las autoridades jerarquizaron su lugar en la institución y promovieron clases de diferentes disciplinas y también, competencias inter-facultades y universidades. ${ }^{41}$ El rector Lennon señaló que su gestión había presenciado los más altos índices de participación estudiantil en actividades deportivas subrayando que los estudiantes habían dado una respuesta disciplinada. Si bien el acceso a las clases era arancelado y exclusivo para los alumnos de las facultades ${ }^{42}$, las Memorias de la UBA dan cuenta de una numerosa asistencia y una activa participación en las competencias. Desde las Direcciones de Deportes de las áreas de Asuntos Estudiantiles del rectorado se organizaban torneos de las más variadas disciplinas deportivas, y se fomentaba la participación en torneos inter-facultades e inter-universidades. ${ }^{43}$

Las reuniones con los jóvenes ingresantes o estudiantes sobresalientes y las actividades culturales, recreativas, deportivas organizadas desde las facultades y el rectorado nos dan muestras de una política activa hacia el estudiantado. No es posible simplificar que la búsqueda por la despolitización de dicho claustro supuso un total silenciamiento e inactividad. La búsqueda de constituir un estudiantado desmovilizado incluyó estrategias que fueron desde la represión legal e ilegal, el endurecimiento de los reglamentos disciplinarios conjugado con una vigilancia continua de la vida universitaria, hasta un conjunto de medidas a partir de las cuales estos jóvenes actores pudieran canalizar demandas e inquietudes. Estos espacios estaban regulados y supervisados por las autoridades. ${ }^{44}$

\section{Y una comunidad subordinada también}

Como mencionamos al inicio del presente apartado, mientras que la modalidad de gobierno de las universidades encontró acuerdo entre rectores y ministros, el problema de la autonomía universitaria conllevó ciertos debates. De este modo, el recambio acelerado de los primeros rectores civiles interventores en la UBA estuvo vinculado con las diferencias que surgieron entre estos y las autoridades nacionales, tanto de la cartera educativa como de la Junta de Gobierno.

39 Marta Philp, "La Universidad Nacional de Córdoba y la "formación de las almas". La dictadura de 1976" en Universidad Nacional de Córdoba. Cuatrocientos años de historia, eds. Daniel Saur y Alicia Servetto, (Córdoba, 2013); Pablo Buchbinder, "La Universidad de Buenos Aires bajo la dictadura: una aproximación a través del perfil, discurso y propuestas de dos de sus rectores" (ponencia presentada en el XI Jornada de Sociología, Buenos Aires, UBA, 2015).

40 Laura Luciani, Juventud en dictadura: representaciones, politicas y experiencias juveniles en Rosario: 1976-1983 (La Plata: UNLPUNAM-UNGS, 2017).

41 Ajedrez, atletismo, básquet, buceo, fútbol, esgrima, gimnasia y aerobismo, hándbol, hockey, natación, pelota paleta, tenis, tenis de mesa, rugby, tiro, vóley, vela, entre otras. Las memorias son muy minuciosas en cuantificar cuántos estudiantes asistían a las prácticas deportivas, las participaciones en torneo y los resultados obtenidos en cada una, destacando las victorias y los podios alcanzados. En las resoluciones rectorales observamos que todas estas actividades eran aranceladas y que los montos a pagar se actualizaban periódicamente a la par que el resto de los aranceles universitarios.

42 Resolución $\mathrm{N}^{\circ} 105$ (Buenos Aires, 31/03/1981), Rectorado de la UBA.

43 "Memorias de la Universidad de Buenos Aires", (Buenos Aires: 1979-1982), Rectorado, Archivo Histórico de la UBA.

44 Esta política de generar actividades y espacios de expresión de cierto sector del estudiantado no supuso la satisfacción de la totalidad de inquietudes estudiantiles. Cf. Guadalupe Seia, "Militancia, oposición y resistencia estudiantil en la Universidad de Buenos Aires durante la etapa final de la última dictadura (1981-1983)”, op. cit., (cita 16). 
Tales fueron los casos de Alberto Constantini y Luis Cabral, quienes señalaron la necesidad de preservar cierta autonomía respecto de la administración de las casas de estudio. Esta demanda contradecía uno de los pilares de la propuesta dictatorial para la universidad: la subordinación total de las casas de estudio respecto del PEN. Es interesante abordar estas disputas sobre la transformación de las casas de altos estudios en tanto nos permiten apreciar la heterogeneidad del régimen dictatorial y de la existencia de matices y concepciones diferentes entre los actores relevantes de la aplicación de la política universitaria. ${ }^{45}$

Alberto Constantini fue el sucesor del delegado militar Said, desde agosto de 1976. Según sostuvo, en el proceso de "reconstrucción de las aulas" y la jerarquía académica de la UBA, la libertad (de expresión, de investigación y creación en la cátedra) sería central. ${ }^{46}$ Para él, la fuerza de la Universidad residía en su independencia y autonomía. De este modo, aspiraba a que "(...) el proceso de reorganización y normalización culmine en el reconocimiento y vigencia de ese principio (...) que es el carácter esencial de la institución." ${ }^{47} \mathrm{Al}$ respecto era tajante, tan pronto como fuera superada la "amenaza subversiva" había que "normalizar la universidad".

Este punto no era coincidente con el planteo ministerial. El ministro Ricardo Bruera aclaró inmediatamente que se concebía “(...) a la universidad y a su autonomía como elementos que pueden y deben integrarse dentro de una concepción de la política nacional y consecuentemente de la política educativa" en tanto planeamiento global que organizaba a las instituciones de "modo coherente con el desarrollo nacional". ${ }^{48}$ La cuestión de la autonomía se constituyó como una disputa profunda entre Bruera y Constantini. Mientras la máxima autoridad educativa repudiaba un modelo universitario basado en la autonomía de las casas de estudio, para Constantini el proceso de destrucción (y caída del nivel académico) de las mismas tenía que ver con el ataque de los gobiernos a su autonomía, siendo 1945, 1966 y 1973 hitos claves del mismo. ${ }^{49}$

Las diferencias se agudizaron cuando fueron publicados los lineamientos del MCE para el nuevo "Sistema Nacional de Enseñanza Superior", donde quedaba de manifiesto que el objetivo era la centralización de las definiciones de política universitaria en el ministerio. La universidad se convertiría en una unidad de ejecución, similar a los institutos terciarios. En función de estas novedades, Constantini no dudó en reivindicar las facultades de auto-administración: "La universidad necesita indispensablemente, estructurar por sí el planeamiento ge-

45 Paula Canelo, El proceso en su laberinto. La interna militar de Videla a Bignone, op. cit., (cita 6); Laura Rodríguez, Católicos, nacionalistas y politicas educativas durante la última dictadura (1976-1983) op. cit., (cita 6).

46 Diario La Opinión, Buenos Aires, 16/07/1976.

47 "Palabras al asumir el cargo de rector de la UBA", (Buenos Aires, 06/08/1976), A. Constantini, Archivo Histórico de la UBA.

48 "Discurso de R. Bruera”, (Buenos Aires, 06/08/1976), Archivo Histórico de la UBA.

49 "Palabras del rector de la UBA en la Facultad de Arquitectura", (Buenos Aires, 09/08/1976) A. Constantini, Archivo Histórico de la UBA; "Palabras del rector de la UBA en la Carrera de Psicología", A. Constantini, (11/08/1976), Archivo Histórico de la UBA. Vale destacar que la fecha de 1945 es identificado con los inicios de las políticas del peronismo en el Estado Nacional. 1966 es el año del golpe de estado perpetrado por Juan Carlos Onganía, cuando tuvo lugar la llamada "Noche de los Bastones Largos". En cambio, 1973 es el año en que el peronismo accede al Poder Ejecutivo a través del voto popular. Las tres instancias son asociadas con intervenciones desde el Estado a las casas de altos estudios. 
neral de las actividades universitarias y determinar la orientación general de la enseñanza, en función de las necesidades o requerimientos nacional, regional o local." 50

Este debate no se limitó al intercambio de impresiones acerca de cómo debía concebirse a las universidades. En los hechos cuando Constantini se disponía a anunciar las nuevas condiciones de ingreso, el MCE ordenó que se detuvieran las gestiones ya que se dictaría una normativa general. El rector acordaba con la perspectiva general del "PRN" respecto del crecimiento desmedido de la matrícula de la UBA producto del ingreso irrestricto. En este sentido, coincidía en la necesidad de implantar el examen de ingreso. Sin embargo, sostenía que los criterios y condiciones así como los cupos debían fijarlos decanos y rectores. ${ }^{51}$

Las tensiones entre el rector de la máxima universidad nacional y el ministro de educación acapararon la atención de la prensa e incluso del presidente de facto Jorge Videla, quién exigió un encuentro con ambos funcionarios para homogeneizar criterios generales. A pesar de dicho acercamiento, el rector porteño no asistió a las reuniones entre los demás rectores de las UUNN y Bruera donde se fijaron el número de ingresantes por carrera, los criterios y condiciones de acceso al sistema universitario nacional. En función de dichos sucesos, Constantini presentó su renuncia. El ingeniero sostuvo que la autonomía académica y la libertad de cátedra eran pautas básicas irrenunciables, y estas orientaciones no eran compartidas por el MCE que obraba en pos de consolidar un sistema de centralización, convirtiendo a las casas de altos estudios en "simples unidades de ejecución".

El decano de la Facultad de Derecho, José Luis Cabral, fue designado como rector en reemplazo de Constantini en febrero de 1977. Al asumir sus funciones decanales, se había definido como un defensor de la libertad de cátedra y de la autonomía de la gestión universitaria, entendida como "autarquía de la universidad". ${ }^{52}$ Como rector, insistió en la necesidad que tenía la universidad de gozar de dichos principios elementales, pero que eso no implicaba que fuera una "ínsula". ${ }^{3}$

A mediados de 1978, el Ministro de Educación Catalán (reemplazante de Bruera) anunció que el sistema educativo sería reformado. Las "Pautas para la Organización Académica de las Universidades Nacionales" disponían la regionalización y la eliminación de las facultades y carreras superpuestas. ${ }^{54}$ Esto provocó la reacción negativa de Cabral que resolvió, junto a los decanos de la UBA, que esa institución estaba eximida de dar cumplimiento a la resolución apoyándose en la autonomía. El rector sostenía que desde la universidad porteña no podían admitir que se le impusiese el cumplimiento de normas que "solo po-

50 Diario La Opinión, Buenos Aires, 29/08/1976, op. cit., (cita 46).

51 Diario La Nación, Buenos Aires, 06/09/1976, op. cit., (cita 46).

52 La "libertad académica" incluía independencia para formular planes de estudio y contenidos de materias, de enseñar sin arreglo a "verdades oficiales", de decidir cuándo el alumno había adquirido la capacitación suficiente y quién está en condiciones de ser profesor, de investigar libremente.

53 "Palabras del rector al asumir sus funciones" (Buenos Aires, 22/02/1977) L. Cabral, Archivo Histórico de la UBA.

54 Cf. Laura Rodríguez, Universidad, peronismo y dictadura. 1973-1983, op. cit., (cita 7). 
drían encontrar justificación si se tratara de una casa de estudios carente de la jerarquía científica y docente, de la tradición y del prestigio". ${ }^{55}$ Ante esto, Catalán acusó al rector porteño de "lesión y desconocimiento público de su autoridad" y le pidió la renuncia. Cabral se negó, entonces el ministro procedió a "limitar sus funciones", lo que equivalía en la práctica a dejarlo cesante. Ante esta polémica situación, el presidente de facto Videla le pidió la renuncia al ministro y también, despidió a Cabral.

Entendemos que estos conflictos permiten observar que para diferentes autoridades del MCE, la autonomía universitaria constituía un obstáculo para el ordenamiento y la "normalización" de los claustros, más que una meta a lograr. Los dos primeros rectores civiles de la UBA durante la etapa dictatorial, en cambio, consideraban necesario un margen de independencia académica e ideológica para la realización de las tareas de estudio, enseñanza e investigación propias de una universidad. Estas miradas contrapuestas se dieron a pesar de que ambos funcionarios interventores habían sido designados por las autoridades de la cartera educativa. En términos generales, coincidían con la necesidad de eliminar la "amenaza subversiva" en los claustros y de "redimensionar" el sistema universitario que había crecido desproporcionadamente en los años anteriores. Sin embargo, no dudaron en manifestar sus discrepancias en materia de administración y gobierno de las instituciones universitarias. Por un lado, postularon la importancia de la libertad de enseñanza e investigación, y por otro, afirmaron el papel que le correspondía a la propia "comunidad académica" (claustro profesoral) en la orientación de las asignaturas, ingresos y también en la apertura y cierre de carreras, en contraposición a los planes de creciente centralización de la política universitaria del MCE.

Estas diferencias implicaron su alejamiento del rectorado de la universidad más importante de Argentina. Desde el MCE no podía aceptarse tales discrepancias de criterios, su exposición pública y el cuestionamiento abierto y directo a los planes de "reordenamiento" y "re-dimensionamiento" del sistema universitario diagramados. Asimismo, era nocivo que dichas críticas fueran efectuadas por las máximas autoridades de una casa de estudios que tenía gran prestigio académico y protagonismo político, y concentraba la atención de la prensa nacional. La autonomía no solo representaba un obstáculo para el desarrollo de la política universitaria nacional, sino también una bandera histórica de la Reforma Universitaria. Como hemos sostenido, la "universidad reformista" era vista como el espacio que estimuló la politización estudiantil, a la vez que posibilitó la "penetración comunista".

Así, la ley 22.207 aprobada en 1980 sostenía que la universidad era una instancia administrativa del gobierno, situación que ponía en evidencia la limitación a la autonomía. Para el ex rector Constantini la dependencia era total respecto del poder político ya que las autoridades eran elegidas por el PEN. ${ }^{56}$ En debate con

55 Diario La Prensa, Buenos Aires, 30/08/1978, 8.

56 “Editorial”, Revista Criterio, N¹799, Buenos Aires, noviembre de 1979. 
estas miradas, el Subsecretario de Políticas Universitarias Sergio Ventura, sostenía que la universidad era autárquica en tanto derecho administrativo, pero no autónoma como los estados soberanos. Afirmaba: “(...) no creo que después de leído el proyecto alguien que pueda pensar que interpreta los postulados de la reforma, que nació signada por la revolución rusa del 17." ${ }^{57} \mathrm{Al}$ respecto, el rector Lennon sostenía que era un "hito histórico" que la nueva ley enterrara definitivamente la reforma. ${ }^{58}$

La ley y sus voceros explicitaban la noción de universidad que la dictadura había construido: una institución que dependía directamente del gobierno nacional con la intermediación de los funcionarios de la cartera educativa. La misma no podía ni debía elegir sus propias autoridades, aprobar su estatuto, definir sus planes de estudios y programas sin la supervisión y autorización del PEN. Se trataba no solo de una casa de estudios dependiente sino también jerárquica en la que los decanos debían responder al rector, el rector al ministro y al presidente de la nación y donde las posiciones de los demás actores universitarios tenían escasa relevancia o ninguna como era el caso de los estudiantes. La tradición reformista era borrada limitando cualquier rastro de autonomía y confirmando la eliminación del co-gobierno. Así, la universidad que buscaba dejar la dictadura era una institución de educación superior reducida en su tamaño (matrícula estudiantil, plantel docente, institutos, etc.), despolitizada y desmovilizada en la que los jóvenes argentinos concurrieran a sus aulas exclusivamente a recibir formación para desempeñarse como profesionales.

\section{Un desafío a la dictadura: la recuperación y re-significación de la tradición reformista}

Hacia finales de 1981, era evidente que la gestión de Roberto Viola (sucesor de Videla) no había resuelto los problemas del régimen a través de sus propuestas moderadas y de diálogo político. La cuestión económica continuó agravándose y con ella la movilización gremial continuó aumentando. ${ }^{59}$ En diciembre de ese año, Viola fue reemplazado por el Leopoldo Galtieri, representante del ala dura de las FFAA. El 30 de marzo de 1982, en la movilización "paz, pan y trabajo" convocada por la CGT-Brasil, se concentraron múltiples sectores, incluidas las agrupaciones universitarias. Fue una convocatoria sumamente numerosa y fuertemente reprimida. ${ }^{60}$ Apenas tres días más tarde, el 2 de abril de 1982, Galtieri anunció el desembarco en Puerto Argentino en las Islas del Atlántico Sur, iniciando las acciones bélicas contra Gran Bretaña. ${ }^{61}$

57 Revista Confirmado, “La pelea por..., Año 14, №497, 12 de julio 1979, 14-18.

58 "Subcomisión No. 3", (Buenos Aires, 1980), Lennon en Comisión de Asesoramiento Legislativo, Archivos Abiertos Ministerio de Defensa.

59 Hacia fines de 1981, con la inflación de 200\%, el PBI industrial cayó 22\% desde fines de 1980, mientras que el PBI global 9\%. La desocupación crecía y caían los salarios reales. Cf. Marcos Novaro y Vicente Palermo, La dictadura militar, op. cit., (cita 10$), 386$.

60 Hubo unos 2.000 detenidos. Revista Aquí y Ahora, Año II, No. 28, (Buenos Aires, 1982).

61 Diario La Nación, 03/04/1982, pág. s/d. Con el inicio de esta guerra se procuraba obtener un importante capital político para un régimen cuestionado desde numerosos sectores, así como también propugnaba reforzar la cohesión interna de las FF.AA. y generar 
En la UBA, el propio inicio del conflicto implicó cambios fundamentales en la vida cotidiana de los claustros. Esto se dio en un marco de gran efervescencia y movilización social en respaldo (completo o parcial) a la intentona de recuperar las islas sureñas. Ese clima de movilización también penetró los claustros, llevándose por delante a las fuerzas de seguridad que vigilaban cada pasillo y a las autoridades universitarias que velaban por el cumplimiento absoluto de los estatutos donde la actividad política estaba prohibida. En las facultades de Ciencias Económicas, Derecho, Ingeniería, Agronomía, Medicina, Ciencias Exactas, Filosofía y Letras, los militantes aprovecharon la conmoción social para instalarse físicamente en las facultades con sus mesas y algunos materiales, incluso bajo la fachada de recolectar donantes de sangre para los combatientes heridos. ${ }^{62}$

Aunque la vigilancia y el control no desaparecieron ${ }^{63}$, las agrupaciones llegaron para quedarse y las autoridades no estaban "preparadas" para contener dicha efervescencia. Coincidimos con Pedrosa que la guerra resultó un disparador para la política en la universidad más allá de la posición que se adoptara frente a ella. ${ }^{64}$ Las comisiones pro centro que se reunían más o menos regularmente desde 1978 y las agrupaciones utilizaron la coyuntura para blanquear su existencia, ampliando el contacto con los estudiantes y ganando referencia entre ellos. El espacio público volvió a incluir reuniones y debates. Con el anuncio de la rendición incondicional de Argentina frente a las tropas británicas el 14 de junio de 1982, este proceso no se interrumpió sino que se profundizó. Se inició así una nueva etapa para la dictadura, la de la transición institucional signada por una crisis en múltiples niveles y una ascendente movilización, que amplió las posibilidades de los grupos opositores. ${ }^{65}$

El agotamiento del régimen, reactivó las energías creativas y las actitudes disruptivas de los jóvenes en la universidad, coincidiendo con las expectativas que concitó el proceso de apertura política. La militancia estudiantil recuperó dinamismo rápidamente y la participación se amplió considerablemente en un contexto de politización y entusiasmo por una campaña electoral que iniciaba. ${ }^{66}$

otro tipo de vínculo con la sociedad. En efecto, la noticia generó una notable movilización a favor de la aventura bélica y un respaldo generalizado al gobierno de la Junta Militar. Aquí nos concentraremos en las implicancias que tuvo el desarrollo del conflicto bélico en la vida universitaria.

62 Entrevistas a Alabarces, Eduardo, P. Berrotarán, A. Delich, Buenos Aires, segundo semestre de 2015.

Mónica Beltrán, La Franja. De la experiencia universitaria al desafío del poder (Buenos Aires, Aguilar, 2013); Laura Polak y Juan Carlos Gorbier, El movimiento estudiantil Argentino (Franja Morada 1976-1986), (Buenos Aires: CEAL, 1994); Fernando Pedrosa, "La universidad y los estudiantes frente a la dictadura militar" en Movimientos estudiantiles en la historia de América Latina, eds. Renate Marsiske (México: UNAM, 2002).

63 Los servicios de inteligencia les acercaron a los rectores miembros del CRUN un listado de las 12 principales agrupaciones que actuaban en las universidades nacionales ante la "amenaza" de la conformación de los centros de estudiantes en tanto "comités políticos". "Exposición de la Asesoría de Comunicación Social acerca del accionar de la oposición política y del oponente subversivo sobre el sector estratégico educativo", (Buenos Aires, 1982), Asamblea del Consejo de Rectores de Universidades Nacionales (CRUN), Archivos Abiertos Ministerio de Defensa.

64 Fernando Pedrosa, "La universidad y los estudiantes..., op. cit., (cita 62).

65 Gabriela Águila, Dictadura, represión y sociedad en Rosario, 1976/1983. Un estudio sobre la represión y los comportamientos y actitudes sociales en dictadura (Buenos Aires, Prometeo, 2008).

66 Cuando asumió como presidente Reynaldo Bignone, se anunció la convocatoria a elecciones y el fin de todas las restricciones a la actividad política. 
Hacia fines de 1982 las universidades se erigieron como uno de los escenarios de la protesta social.

Los servicios de inteligencia y los miembros del CRUN expresaban su preocupación ante la creciente movilización. Estos caracterizaban al accionar de las agrupaciones, federaciones y comisiones era identificado como "accionar opositor" ya que violaban la ley universitaria vigente y querían evitar su aplicación en los claustros. Además propugnaban establecer "comités de reclutamiento y agitación" para los partidos políticos, incluso alertaban sobre el accionar "subversivo" que quería recuperar "la universidad de 1973": "facultades politizadas, verdaderos cuarteles de la subversión". Un aspecto que preocupaba especialmente era la instalación del "tema participación estudiantil" ya que eso conllevaba el objetivo último de la recuperación del co-gobierno que era contrario al modelo universitario que las autoridades defendían. Frente a esto era necesario tomar medidas para proteger a la juventud y las "conquistas" del "PRN". ${ }^{67}$

En ese marco, desde el MCE y el rectorado de la UBA apuraron el paso en el proceso de "normalización". ${ }^{68}$ Con la realización de concursos docentes, se prosiguió con la conformación del claustro docente que votaría representantes para el nuevo y restringido gobierno universitario. ${ }^{69}$ El 15 de diciembre de 1982, el PEN autorizó el llamado a elecciones, integrándose así los Consejos Académicos de las facultades, el Consejo Superior y la Asamblea Universitaria. ${ }^{70}$ A partir de entonces, las decisiones que antes recaían exclusivamente en el rector, pasaron a ser responsabilidad de este órgano colegiado conformado por las autoridades designadas directamente por el PEN y profesores ordinarios miembros de los Consejos Académicos de cada unidad.

Para la mayoría de sus críticos, el objetivo de los concursos era uno solo: "establecer la universidad del "Proceso" como un edificio permanente, metamorfoseando la realidad de facto en aparente legalidad." ${ }^{71}$ Éstos denunciaban el proceso de "normalización" como una "maniobra continuista" para garantizar la permanencia de los docentes amigos del régimen y así, condicionar al próximo gobierno constitucional. ${ }^{72}$ Sostenían además que se buscaba dotar de un "barniz" de legalidad y constitucionalidad a una situación que se había configurado bajo el gobierno de facto y la intervención de las casas de estudio. La FUA sos-

67 "Exposición de la Asesoría de Comunicación Social...", (Buenos Aires, 1982), "Parte de Inteligencia 20/82", MCE (Buenos Aires, 1982), Asamblea del Consejo de Rectores de Universidades Nacionales (CRUN), Archivos Abiertos Ministerio de Defensa.

68 Cf. Guadalupe Seia, "La búsqueda por la institucionalización y 'normalización universitaria' de la última dictadura en Argentina Ley universitaria, nuevo estatuto y concursos docentes en el caso de la Universidad de Buenos Aires (1980-1983)", Debate Universitario 6, (2017).

69 Resolución. No1366, (Buenos Aires, 19/11/1982), Rectorado UBA.

70 "Informe Secretaría Académica", Memorias de la UBA 1982, Rectorado, Buenos Aires, 1983, 11, Archivo Histórico de la UBA.

71 Anónimo, "Concursos universitarios o las triquiñuelas del continuismo", Revista Perspectiva Universitaria, No.11, Diciembre, 1982.

72 En una línea similar se expresaron las agrupaciones Franja Morada, Movimiento Nacional Reformista, Movimiento Reformista 15/6, Movimiento de Orientación Reformista, LUCHA, Unión Nacional de Estudiantes, Movimiento al Socialismo, Juventud Universitaria Peronista, Bloque Peronista, Movimiento Independiente Universitario, entre otros. En ese número de la Revista Perspectiva Universitaria se encuentran reunidos una gran variedad de posicionamientos estudiantiles sobre la cuestión. Los medios de comunicación también daban cuenta que desde diversas asambleas, agrupaciones y centros de estudiantes ya constituidos se emitían documentos condenatorios de los concursos y se exigía su suspensión (Diario Clarín, 26/11 y 22/12/1982; Diario La Voz, 23 y 26/11/1982; Diario La Nación, 05 y 15/12/1982). 
tenía que la: “(...) normalización pretende garantizar el continuismo, condena a los verdaderos maestros de la juventud a que no accedan por muchos años a la docencia universitaria, y se implementan concursos docentes arbitrarios, ajenos a la participación de los claustros con la intención de perpetuar a los servidores del proceso, incluso durante el ejercicio de un futuro gobierno constitucional."73

Más allá de los escasos espacios institucionales abiertos por la dictadura para la discusión de la propuesta de ley, la circulación de la misma en los medios de comunicación abrió otros espacios que posibilitaron un interesante volumen de debate entre diferentes especialistas en materia educativa, políticos y ex funcionarios de la cartera educativa e incluso militantes estudiantiles. Estas discusiones y manifestaciones públicas se fueron multiplicando al momento del desarrollo de los concursos. Después de la finalización de la guerra de Malvinas los estudiantes avanzaron en articular cierta movilización y una de sus consignas fue la nulidad de estos concursos. El cuestionamiento a estos concursos y el "continuismo" dictatorial en la universidad sumado a la condena de la educación restrictiva y elitista se articuló en una crítica global a la política universitaria del "PRN". Dicho planteo global se cristalizó en el cuestionamiento a la ley universitaria como la expresión normativa del modelo universitario impulsado por el MCE. En ese sentido, la movilización contra los concursos docentes y la búsqueda de las autoridades de heredar una universidad "en orden, jerárquica y de acuerdo a los valores cristianos occidentales".

Asimismo, el cuestionamiento a la "normalización" como fin y a los concursos como medio incorporó el "tema de la participación estudiantil" ya que la ley establecía que el gobierno de la -UBA recaería exclusivamente sobre una minoría de profesores titulares y las autoridades designadas por el PEN. A los estudiantes les correspondía un lugar pasivo y secundario, adquiriendo enseñanzas de sus profesores y aceptando los espacios cedidos para su expresión (boletines, entrevistas, encuestas, etc.). Las agrupaciones estudiantiles exigían ser escuchadas y obtener el lugar que ellos consideraban que al claustro estudiantil le correspondía en la casa de altos estudios.

Ante la urgencia por "acomodarse" a una transición nada amigable para los adeptos al régimen, este proceso de institucionalización a través de la ley 22.207, el estatuto, los concursos y la "normalización" implicaban un objetivo, no necesariamente coherente ni mucho menos inmediato, de cristalizar y prolongar un estado de situación de los claustros lograda: la desactivación del accionar del movimiento estudiantil y de la efervescencia social radicalizada hacia la izquierda; la desvinculación entre las agrupaciones estudiantiles y la mayoría de los estudiantes; el achicamiento de las unidades académicas; $y$, el recorte de contenidos "apátridas, no occidentales ni cristianos". Así, se lograba la histórica meta de "enterrar" a la Reforma que proponía una universidad autónoma y co-gobernada con la participación de los estudiantes para construir una universidad jerárquica, antidemocrática, dependiente (y obediente) del poder político.

73 “Declaración de la FUA", RPU, No. 11/12, (diciembre 1982-enero 1983): 94-95. En octubre, la misma organización exigía la derogación de la ley, la suspensión de los concursos. 
A partir de las críticas mencionadas, desde los diversos sectores políticos, se comenzaba a articular a grandes rasgos un modelo alternativo de universidad. En este marco, el rescate de la tradición reformista por una gran parte de la militancia estudiantil fue central. La autonomía y el co-gobierno con participación estudiantil eran dos de los pilares para construir una universidad democrática en la que todos los miembros de la comunidad tendrían espacio para la expresión. Solo así, afirmaban, se podría poner fin a la universidad jerárquica, autoritaria y anti-democrática de la dictadura. Observamos cómo ya para fines de 1982, el movimiento estudiantil había generado un planteo global de oposición a la dictadura en materia universitaria, y este, además se articulaba con el movimiento social y político nacional que desde diferentes sectores bregaba por el fin de la dictadura y la transición a un sistema democrático. La universidad debía ser democrática como el nuevo gobierno, atendiendo al desarrollo nacional.

La "democracia" como modelo opuesto a la "dictadura" era colocada en un lugar central del debate político nacional y en la universidad también. El ideario reformista focalizado en la modalidad de gobierno universitario funcionaba muy bien en dicha construcción discursiva, la universidad reformista/democrática era la que la dictadura había querido eliminar para construir una universidad autoritaria (represiva) y anti-popular. Entonces, el reformismo fue revalorizado por su contenido democrático a la par que las ideas de transformación radical/revolucionaria de la sociedad -y la universidad- perdía espacio entre los discursos mayoritarios de las agrupaciones estudiantiles. La transformación que se definía como urgente y necesaria era la democracia.

Vale destacar que a diferencia de los casos de Rosario y La Plata ${ }^{74}$, en Buenos Aires la movilización estudiantil no logró que el proceso de concursos docentes se detuviera ni impidió que se conformara un gobierno de una minoría profesoral y otros funcionarios simpatizantes del régimen. Sin embargo, como hemos señalado, la creciente movilización estudiantil (contra el "continuismo", el ingreso restringido, el arancel) fue la que posibilitó la reconstrucción de los centros de estudiantes a pesar de que la normativa universitaria continuaba prohibiendo todo tipo de actividad gremial o política. $^{75}$

\section{CONCLUSIÓN}

A lo largo del presente artículo hemos abordado uno de los principales rasgos del proyecto universitario de la última dictadura en Argentina: su anti-reformismo. En los diagnósticos elaborados por las FFAA y las autoridades educativas, la Reforma Universitaria de 1918 es localizada como el origen del proceso de infiltración comunista en las universidades. En particular, la participación estudiantil en el gobierno universitario promovía su politización y radicalización. La

\footnotetext{
74 En estas universidades sus rectores (que se habían mantenido a la cabeza de dichas instituciones durante toda la etapa) se vieron obligados a renunciar ante la creciente movilización estudiantil que exigía la eliminación de los cupos.

75 Cf. Guadalupe Seia, “Militancia, oposición y resistencia estudiantil..., op. cit., (cita 6).
} 
universidad en tanto ente autónomo era un espacio propicio para la realización de actividades subversivas, desorientando a la juventud y extendiendo el caos social.

La universidad que se promovía desde el MCE era una institución subordinada al poder político nacional, donde este interviniera de manera directa para sanear y ordenar los claustros: aprobando contenidos, asignaturas, planes de estudio, seleccionando a las autoridades, definiendo la contratación o el despido de los docentes, así como también los criterios para ingresar en cada carrera.

A través de las diversas normativas aprobadas a lo largo de la etapa, de la intervención civil y militar de las casas de estudio, de los cambios en la estructura y el funcionamiento de la UBA, se constituyó una institución subordinada, jerárquica y antidemocrática en la que los estudiantes tenían espacios regulados para la participación en la vida universitaria pero no injerencia en los asuntos del gobierno.

Los estudiantes de la universidad dictatorial no debían (ni podían) participar de las decisiones sobre los asuntos universitarios, no podían desarrollar actividades políticas o gremiales, no podían movilizarse ni organizarse bajo formas ilegales (centros de estudiantes, agrupaciones, federaciones). La juventud universitaria podía y debía realizar actividades culturales y deportivas aprobadas y controladas por las autoridades universitarias. Allí, podían desplegar sus energías e inquietudes.

Sin embargo, como hemos desarrollado en este y otros trabajos, un sector de los estudiantes no se conformó con dichos espacios ofrecidos sino que generó redes y opciones de participación y discusión más allá de las permitidas. Cuando el clima político lo posibilitó, estas comisiones, revistas y agrupaciones volvieron a desarrollar actividades públicas en las facultades planteando una serie de críticas a la situación universitaria, que progresivamente se articularon en un cuestionamiento a la política universitaria de la dictadura. En contraposición a su modelo antidemocrático, jerárquico y subordinado al poder político, comenzaron a delinear un modelo de universidad democrática recuperando las banderas históricas del reformismo: la participación estudiantil en el co-gobierno universitario, sin miembros seleccionados por el PEN y sin la injerencia de este último en los asuntos propios de cada casa de estudio.

A partir de lo desarrollado es posible identificar dos procesos contrapuestos que se entretejen en el pasado reciente de las UUNN. Por un lado, los avances anti-reformistas de las autoridades interventoras. Por otro, la recuperación y re-significación del reformismo como orientador de la resistencia contra el modelo universitario de la dictadura. En ese sentido, es posible dejar planteadas las limitaciones y obstáculos que la militancia estudiantil le planteo al proyecto autoritario. Debemos dejar abiertos interrogantes para profundizar en los sentidos y las orientaciones con que las banderas reformistas fueron retomadas en el nuevo contexto institucional y político en el cual los proyectos de transformación radical de la sociedad fueron derrotados por el "Proceso de Reorganización Nacional". 


\section{FUENTES}

\section{Fuentes Documentales}

Archivos Abiertos, Centro de Documentos "Edificio Cóndor", Ministerio de Defensa de la Nación. Poder Ejecutivo Nacional. Ley № 21.276 “Prioridad para la normalización de las universidades nacionales", Buenos Aires, 1976.

Archivos Abiertos, Centro de Documentos “Edificio Cóndor", Ministerio de Defensa de la Nación. Poder Ejecutivo Nacional. “Bases para la intervención de las fuerzas armadas en el proceso nacional". Buenos Aires, 1976.

Archivo Histórico de la UBA. Rectorado y Secretaría de Prensa y Difusión. "Discursos, Comunicados de Prensa, de Ministros, Rectores y Decanos de la UBA." Buenos Aires, 1974-1983.

Archivo Histórico de la UBA. Rectorado: Memorias de la UBA. Años 1979-1982. Buenos Aires, 19791983.

Resoluciones Rectorales, 1974-1983. Secretaría de Coordinación del Consejo Superior de la UBA.

\section{Testimonios}

Entrevistas a Claudio Spiguel, Carlos Astarita, Alberto Lettieri y Magdalena Frere (2013), realizadas por los miembros del Programa "Universidad y Dictadura” de la Cátedra Libre de DD.HH. de FFyL y disponibles para la consulta en el Centro de Documentación del mismo nombre, localizado en la sede Púan de dicha unidad académica.

Entrevistas realizadas a Andrés Delich, Eduardo, Pablo Alabarces, Patricia Berrotarán, Juan Pablo Paz, realizadas por Guadalupe Seia durante 2015. Buenos Aires.

\section{REFERENCIAS}

Águila, Gabriela. Dictadura, represión y sociedad en Rosario, 1976/1983. Un estudio sobre la represión y los comportamientos y actitudes sociales en dictadura. Buenos Aires: Prometeo, 2008.

Águila, Gabriela. “La Universidad Nacional de Rosario en dictadura (1976-1983): depuración, "normalización" y reestructuración institucional". PolHis, Año 7, No. 14 (2015).

Algañaraz Soria, Víctor. "Reestructuración universitaria en clave autoritaria: política y accionar de los rectores de la Universidad Nacional de San Juan durante la última dictadura militar (19761983)". PolHis, Año 7, No. 14 (2015).

Beltrán, Mónica. La Franja. De la experiencia universitaria al desafio del poder. Buenos Aires: Aguilar, 2013.

Biagini, Hugo, "La cultura de la resistencia juvenil y el proceso emancipador". Revista Historia de la Educación Latinoamericana, No.11 (2008).

Buchbinder, Pablo. “La Universidad de Buenos Aires bajo la dictadura: una aproximación a través del perfil, discurso y propuestas de dos de sus rectores". (Ponencia presentada en las XI Jornadas de Sociología, UBA, Buenos Aires, 2015).

Buchbinder, Pablo. Historia de las universidades argentinas. Buenos Aires: Sudamericana, 2010.

Buchbinder, Pablo. ¿Revolución en los claustros? La Reforma Universitaria de 1918. Buenos Aires: Sudamericana, 2008.

Califa, Juan. Reforma y revolución. La radicalización politica del movimiento estudiantil de la UBA 1943-1966. Buenos Aires: EUDEBA, 2014.

Donoso Romo, Andrés, "Constantes en los movimientos estudiantiles latinoamericanos: aproximación a partir del caso chileno de 2011". Revista Historia de la Educación Latinoamericana, Vol. 19, No. 28 (2017).

Daros, William, “Incidencias del proceso histórico en el proceso educativo argentino". Revista Historia de 
la Educación Latinoamericana Vol. 16, No. 22 (2014).

Duhalde, José. El Estado Terrorista Argentino. Buenos Aires: Colihue, 2013.

Estado Mayor General del Ejército. Marxismo y Subversión. Ámbito educacional. Buenos Aires, 1980.

Fuerzas Armadas. El Terrorismo en Argentina. Buenos Aires, 1977.

Kaufamnn, Carolina (dir.), Dictadura y Educación (1976-1983), Tomos I y II. Buenos Aires: Miño y Dávila, 2001 y 2003.

Landívar, Gustavo. La Universidad de la Violencia. Buenos Aires: Ediciones de Palma, 1980.

Luciani, Laura. Juventud en dictadura: representaciones, políticas y experiencias juveniles en Rosario: 19761983.La Plata: UNLP-UNAM-UNGS, 2017.

Novaro, Marcos y Vicente Palermo. La dictadura militar. (1976- 1983). Del golpe de Estado a la restauración democrática. Buenos Aires: Paidós, 2003.

Canelo, Paula. El proceso en su laberinto. La interna militar de Videla a Bignone. Buenos Aires: Prometeo, 2009.

Pedrosa, Fernando. "La universidad y los estudiantes frente a la dictadura militar". En Movimientos estudiantiles en la historia de América Latina, editado por Renate Marsiske. México: UNAM, 2002.

Philp, Marta. "La Universidad Nacional de Córdoba y la "formación de las almas". La dictadura de 1976". En Universidad Nacional de Córdoba. Cuatrocientos años de historia, editado por Daniel Saur y Alicia Servetto. Córdoba: UNC, 2013.

Polak, Laura y Juan Carlos Gorbier. El movimiento estudiantil Argentino (Franja Morada 1976-1986). Buenos Aires: CEAL, 1994.

Rodríguez, Laura y Germán Soprano. “La política universitaria de la dictadura militar en la Argentina: proyectos de reestructuración del sistema de educación superior (1976-1983)". Nuevo Mundo Mundos Nuevos, (2009).

Rodríguez, Laura. Católicos, nacionalistas y políticas educativas durante la última dictadura (1976-1983). Rosario: Prohistoria, 2001.

Rodríguez, Laura. Universidad, peronismo y dictadura. 1973-1983, Buenos Aires: Prometeo, 2015.

Rodríguez, Laura. "Los ministros de educación en Argentina (1854-2015): análisis de los perfiles profesionales de las élites políticas". História da Educação 21, No. 51, (2017).

Seia, Guadalupe. "El movimiento estudiantil de la Universidad de Buenos Aires (UBA) entre la Guerra de Malvinas y la salida democrática (1982-1983). Un estudio de caso sobre la Facultad de Ciencias Exactas y Naturales (FCEN)". (Ponencia presentada en el "IX Seminario Internacional Políticas de la Memoria", Buenos Aires, 2016).

Seia, Guadalupe. “La Universidad de Buenos Aires (UBA) entre la 'Misión Ivanissevich' y la última dictadura (1974-1983). Represión, 'reordenamiento' y reconfiguraciones de la vida estudiantil". Tesis de Maestría en Historia Contemporánea, Universidad Nacional de General Sarmiento, 2016.

Seia, Guadalupe. “Las Revistas Estudiantiles en la Universidad de Buenos Aires durante la última dictadura (1976-1983). Un estudio exploratorio sobre las prácticas culturales del estudiantado universitario en la Facultad de Ciencias Exactas y Naturales". (Ponencia presentada en el I Coloquio de Historia de las Juventudes, La Condición Juvenil en América Latina, Ciudad de México, 2017).

Seia, Guadalupe. "Militancia, oposición y resistencia estudiantil en la Universidad de Buenos Aires durante la etapa final de la última dictadura (1981-1983)". Historia, voces y memoria, No. 9, 2016.

\begin{tabular}{l|l} 
& \\
\hline $\begin{array}{l}\text { Seia, Guadalupe A. “La dictadura contra la Reforma } \\
\text { Universitaria. Orientación de la política universitaria en la }\end{array}$ & \\
$\begin{array}{l}\text { Universidad de Buenos Aires (1976-1983)". Revista Historia } \\
\text { de la Educación Latinoamericana. Vol. } 20 \text { No. } 30 \text { (2018): 193-216. }\end{array}$ \\
\hline
\end{tabular}

